\title{
Computed tomography in the early detection of
} asbestosis

\author{
Raymond Bégin, Gaston Ostiguy, Robert Filion, Neil Colman, Pierre Bertrand
}

\begin{abstract}
Computed tomography (CT; both conventional (CCT) and high resolution (HRCT)) scans of the thorax were evaluated to detect early asbestosis in 61 subjects exposed to asbestos dust in Québec for an average of 22(3) years and in five controls. The study was limited to consecutive cases with chest radiographs of the International Labour Organisation categories 0 or 1 determined independently. All subjects had a standard high kilovoltage posteroanterior and lateral chest radiograph, a set of 10-15 $1 \mathrm{~cm}$ collimation CCT scans and a set of three to five $2 \mathrm{~mm}$ collimation HRCT scans in the upper, middle, and lower lung fields. Five experienced readers independently read each chest radiograph and sets of CT scans. On the basis of three to five readers agreeing for small opacities of the lung parenchyma, $12 / 46$ (26\%) negative chest radiographs were positive on CT scans, but $6 / 18(33 \%)$ positive chest radiographs were negative on CT scan. On the basis of four to five readers agreeing on a chest radiograph, $36 / 66$ (54\%) subjects were normal (group A), $17 / 66(26 \%)$ were indeterminate (group B), and 13/66 (20\%) were abnormal (group C). By the combined readings of CCT and HRCT, 4/31 (13\%) asbestos exposed subjects of group A were abnormal (p $<0.001), 6 / 17$ (35\%) of group $B$ were abnormal, and in group $C, 1 / 13$ (8\%) was normal, $2 / 13$ were indeterminate, and 10/13 (77\%) were abnormal. Separate readings of CCT and HRCT on distinct films in 14 subjects showed that all cases of asbestosis were abnormal on both CCT and HRCT.
\end{abstract}

CHU Sherbrooke

R Bégin

Hôpital Maisonneuve-Rosemont, Montréal

G Ôstiguy, R Filion

Montréal General Hospital

N Colman

Hôpital Ste Jeanne d'arc, Montréal, Québec, Canada

P Bertrand
Inter-reader analyses by kappa statistics showed significantly better agreement for the readings of CT than the chest radiographs (p $<0.001$ ), and for the reading of CCT than HRCT (p $<0.01)$. Thus CT scans of the thorax identifies significantly more irregular opacities consistent with the diagnosis of asbestosis than the chest radiograph (20 cases on CT scans $v 13$ on chest radiographs when four to five readers agreed, $13 \%$ of asbestos exposed subjects with normal chest radiographs or $21 \%$ of asbestos exposed subjects with normal or near normal chest radiographs. It decreased the number of indeterminate cases significantly from 17 on chest radiographs to 13 on CT scans. All cases of asbestosis detected only on CT scans were similarly seen on CCT and HRCT and did not have significant changes in lung function. The CT scans significantly reduced the inter-reader variability, despite the absence of ILO type reference films for these scans.

(British fournal of Industrial Medicine 1993;50:689-698)

The current standard criteria for diagnosis of asbestosis are based on an occupational history, interpretation of the chest radiograph by the International Labour Organisation (ILO) standards, ${ }^{1}$ pulmonary function tests, and lung histopathology when available. ${ }^{23}$

Progress in the imaging of several interstitial lung diseases with the use of computed tomography (CT) scans has repeatedly shown that the CT scan can be more sensitive than the chest radiograph for the detection of diffuse lung parenchymal diseases. $^{4-8}$ Given the known absence of change of the chest radiograph in some $10 \%$ of symptomatic patients with established interstitial lung diseases, whether idiopathic or associated with exposure to asbestos $^{9-12}$ or silica, ${ }^{13}$ the finding of an increased sensitivity of the CT scan over the standard chest radiograph is not surprising. We have previously considered this question with conventional CT (CCT) scans and were able to identify specific aspects of the imaging of the pneumoconiotic 
processes where CT scans provided new information and permitted a better clinical appreciation of the pathological process. ${ }^{14-19}$ In coal workers' pneumoconiosis, the report of Rémy-Jardin et al also suggests that CT scans may be useful in achieving more accurate evaluation of parenchymal fibrosis. ${ }^{20}$ We have recently reported on the CT scan in silicosis, indicating that it detects up to $40 \%$ more abnormalities consistent with the diagnosis of silicosis in subjects exposed long term to silica with a normal radiograph and recognised confluence of parenchymal opacities in up to $33 \%$ of cases of radiographic simple silicosis. ${ }^{15} 1921$

In a study of asbestos workers with high resolution CT (HRCT) scans, Staples et al concluded that in their asbestos exposed subjects with normal chest radiographs, HRCT scans identified a group of $57(34 \%)$ subjects with abnormalities suggestive of asbestosis. ${ }^{22}$ The group had a significant loss of lung function. Al-Jarad et al developed an HRTC scoring system to study 60 asbestos workers with various degrees of interstitial lung disease and concluded that the system allowed good interobserver and intraobserver agreement and that scores of disease on HRCT scans and chest radiographs correlated similarly with impairment of lung function. ${ }^{23}$ Their findings are similar to those of our earlier study on CCT scans in asbestosis. ${ }^{14}$

Our present study was designed firstly to consider the question of early detection of diffuse interstitial lung disease in asbestos workers with a chest radiograph already classified in the category 0 or 1 according to the ILO 1980 classification. ${ }^{1}$ The chest radiographs and CT scans were analysed by five experienced readers, through uninformed and independent readings. Secondly, we assessed the effect of reader variability on interpretation of data and thirdly we tested the proposition that asbestosis detected only on CT scans is associated with significant loss of lung function. ${ }^{22}$

\section{Patients and methods \\ SUBJECTS}

The 61 consecutive patients of this study were referred by the Workman's Compensation Board of Québec for evaluation of possible lung disease associated with exposure to asbestos dust in the Québec asbestos industries. All were investigated at either the Maisonneuve-Rosemont or CHUS hospitals. Five healthy non-smoking workers in the same age range as the exposed workers were included on a voluntary basis to serve as non-exposed, age matched controls for the chest radiographs and the $\mathrm{CT}$ scans.

The mean (SEM) age of the 66 subjects of the study was $62(2)$ (range 40-75) years. The 61 subjects exposed to asbestos worked in exposed condi- tions for an average of 22(2) (range one to 42) years. Of the 61 workers, 15 were current cigarette smokers and 33 former cigarette smokers and they had smoked on average 28 (3) pack-years. Thirteen were lifetime non-smokers.

\section{CLINICAL EVALUATION}

All patients had a history taken and underwent physical examination with emphasis on the detection of abnormalities suggesting asbestosis. A questionnaire designed to elicit respiratory symptoms and factors associated with chronic obstructive pulmonary disease, lifetime smoking habits, and occupational history was completed by all subjects. Duration of exposure to asbestos for each worker was taken as the number of years of employment in a work environment containing asbestos dust. Dyspnea was graded according to the method of Crofton and Douglas. ${ }^{24}$

\section{CHEST RADIOGRAPHS}

Standard high kilovoltage posteroanterior and lateral films were taken at maximal inspiration. The radiographs were graded for the number of small opacities by the five readers according to the ILO 1980 classification. $^{1}$ The profusion (number) of opacities was scored with the ILO grading system based on the viewers' assessment of the concentration of opacities compared with standard radiographs provided by the ILO. This classification recognises the existence of a continuum of change, from no opacity to the most advanced category. The scores were converted to a linear scale of 0 to 10 (12 grades) as follows: ILO grade 0/- (clearly normal) and $0 / 0$ (normal after a careful examination) $=0$ on the linear scale; ILO grade $0 / 1=1$; $1 / 0=2 ; 1 / 1=3 ; 1 / 2=4 ; 2 / 1=5 ; 2 / 2=6 ; 2 / 3=7$; $3 / 2=8 ; 3 / 3=9 ; 3 / 4=10$. The profusion of opacities was scored to weight the usual six areas of the lung (upper, middle, and lower left and right fields) seen on the chest radiograph, with emphasis on the abnormalities detected as recommended by the ILO report. ${ }^{1}$

To group patients with similar diseases in the ILO classification, four categories are defined on the basis of the same profusion scores: category 0 $=$ profusion scores $0 /-, 0 / 0,0 / 1$; category $1=$ profusion scores $1 / 0,1 / 1,1 / 2$; category $2=$ profusion scores $2 / 1,2 / 2,2 / 3$; and category $3=$ profusion scores $3 / 2,3 / 3$, and $3 / 4$.

Pleural changes were classified in terms of site, width, and extent according to the ILO classification. For chest walls, the width category a, b, or c and the extent score 1,2 , or 3 were given; diaphragms and costophrenic angles were classified as present or absent. Pleural calcifications were also assessed according to the ILO classification. ${ }^{1}$ A simple total score of pleural changes was developed 
to scale the pleural abnormalities due to asbestos as follows: each diaphragm and each costophrenic angle change was scored as 1 (maximum of 4 ), pleural plaques "en face" were scored as 1 ; the circumscribed pleural plaques classified as $a 1, a 2, b 1$ were scored as $1, a 3, b 2, c 1$ as 2 , and $c 2$ and $c 3$ as 3 for each side of the thorax. The pleural changes classified as diffuse were scored at $2 \times$ the score of circumscribed pleural changes for the same type of ILO classification-that is, a pleural change of b2 ILO classification was scored as 4 when diffuse. With this scale, our subjects had scores of pleural disease that varied between 0 and 16 .

\section{COMPUTED TOMOGRAPHY SCANS OF THE THORAX}

All CT studies were performed with a Picker 1200 SX (Pickers, Highland Heights, Ohio) or Toshiba 900 TS (Toshiba inc, Japan) instrument and included conventional $10 \mathrm{~mm}$ collimation CT (CCT) scans at $1 \mathrm{~cm}$ intervals from the apex of the lung to the base of the diaphragm and three to five high resolution $2 \mathrm{~mm}$ collimation (HRCT) scans taken through the upper, mid, and lower thorax. The images were reconstructed with the use of a bone algorithm. Scans were viewed at window levels most appropriate for pulmonary parenchyma (window level-550 to-650, window width 1500 to 1700). The CT scans were performed with the subject in the prone position during breath holding at full lung capacity. The supine position was not used to avoid misinterpretation of the frequent occurrence of pseudoreticulation in the gravity dependent regions due to accumulation of fluids and physiological atelectasis. We have preferentially used the prone position since the early experience of ourselves and others with patient positioning for the CT scans, ${ }^{14}$ that the mineral dust diseases mostly affect the subpleural lung areas..$^{13} 14$

The profusions of parenchymal opacities seen on the CT scans were graded with the same principles as the ILO 1980 system for grading pulmonary disease on the chest radiograph. It is recognised that CT may partly obliterate the summation effect seen in two dimensional chest radiographs, but nevertheless a grading system can be used, as also suggested in another study with different grading principles. ${ }^{23}$ For our study, we chose grading principles closely related to those of the ILO grading system for chest radiographs. The absence of opacities was graded as a score of the category 0 ( = profusion scores $0 /-, 0 / 0,0 / 1 ; 0 /-=$ clearly normal, $0 / 0=$ normal after a careful examination, and $0 / 1=$ normal after some considerations of category 1 abnormality). The interpretation of definite presence of opacities allowed a grading of the opacities of category 1 or above. If the opacities were not obliterating the vascular markings, they were read in the category 1 grades $(1 / 0,1 / 1,1 / 2)$. If they were obliterating the vascular markings slightly but definitely, they were read in the category 2 grades $(2 / 1$; $2 / 2,2 / 3$ ), and for the most severe blunting of the vascular markings, the opacities were interpreted as category $3(3 / 2,3 / 3$, and $3 / 4)$. We did not score the pleural changes on CT scans.

\section{PULMONARY FUNCTION TESTS}

Lung volumes, flow volume curves, diffusion capacity, and gas exchange at rest were measured according to standard methods ${ }^{25}$ as previously applied. ${ }^{17}$ Functional residual capacity was determined by the helium rebreathing method and diffusion capacity by the single breath carbon monoxide (DLCO) method.

\section{DIAGNOSIS OF ASBESTOSIS}

For the purpose of this investigation, the diagnosis of asbestosis was based on a chest radiograph or a CT scan showing bilateral changes consistent with asbestosis in category 1 or higher, according to the ILO 1980 classification for the radiograph ${ }^{1}$ and considered as definite abnormalities for the CT scan according to earlier reports of CT scans in asbestosis. ${ }^{22} 2326-30$

\section{THE READERS}

The readers included four chest physicians participating in the evaluation of the Québec cases of occupational lung diseases for more than 10 years. Three of them were certified National Institute of Occupational Safety and Health B readers and four had contributed to the Canadian Pneumoconiosis Reading Panel (CPRP) since its initiation. Their independent gradings of chest radiographs had similar reading patterns according to the CPRP. The fifth reader was a chest radiologist interested in the pneumoconioses, who has been interpreting the chest radiographs of some $25 \%$ of the workers of Québec investigated by one committee, for suspected pneumoconiosis during the past seven years.

Chest radiographs and the combined CT scans were read independently by all readers in unrelated sessions, on the basis of current reading practice for each examination. ${ }^{1-32627}$ In an additional session, the CCT and HRCT scans were read independently to assess the value of each type of scan alone and in combination. Each reader interpreted each radiograph and $\mathrm{CT}$ scan independently in specially planned work sessions, with the ILO standard chest radiograph available at all times. The readings were done in three separate sessions, at least one week apart, for the chest radiographs, for the combined CCT and HRCT scans, and for the separate reading of CCT and HRCT scans. Each of the readers recorded his interpretation of the images on a CPRP reporting sheet. 
The data were transferred from the sheets to a database for analyses on a Macintosh computer (Apple computer inc, Cupertino, Calif) with the Statview $512+$ and SuperANOVA programs (Brainpower inc, Calabasas, CA), and the SPSS program (SPSS inc, Chicago, Illinois).

\section{STATISTICAL ANALYSES}

All results are expressed as means (SEM). The data were evaluated by the Mann-Whitney $U$ test for differences between groups, and by the Wilcoxon matched pairs signed rank test for differences between radiological methods. To assess the inter-reader agreement in the reading of the lung opacities on CT or HRCT scans, we used kappa inter-reader agreement statistics and the Spearman non-parametric correlation procedure. We used multiple variate analyses of variance (MANOVA) $)^{31-33}$ to study associations between variables.

\section{Results}

READER AGREEMENT

For reading radiographs and scans as positive or negative, we found kappa values of $0.44(0.08)$ for the radiographs and of $0.63(0.06)(p<0.05)$ for the scans. For reading on the extended ILO scale, kappa values were $0.20(0.04)$ for the radiographs and $0.28(0.03)(p<0.05)$ for the scans. Because the kappa statistics are not designed for scaled data, we also tested the correlations with the nonparametric Spearman correlation procedure. On the concise ILO scale, the readings of the radiographs had an $r$ value of $0.43(0.08)$ and the scans an $r$ value of $0.62(0.04)(\mathrm{p}<0.05)$. On the extended ILO scale, the $r$ value was $0.52(0.07)$ for the radiographs and $0.70(0.04)(\mathrm{p}<0.05)$ for the scans.

We also considered the effect of the level of agreement selected (three to five $v$ four to five readers in agreement) in determining each radiograph or scan as positive or negative (table 1). On the basis of three to five readers in agreement, there were 12/46 (26\%) cases with chest radiographs negative and CT scans positive for asbestosis, as opposed to $4 / 36$ (11\%) on the basis of four to five readers in agreement. Whereas three to five readers in agreement recognised more negative radiographs $(70 \%)$ and negative scans $(40 \%), 26 \%$ of the negative radiographs were read as being positive on the combined CT scan readings and $33 \%$ of the positive radiographs were negative on the scans. On the other hand, the four to five reader agreement category read $54 \%$ of the radiographs as negative and $50 \%$ of the scans as negative but $12 \%$ of the negative radiographs as positive on scans and $8 \%$ of the positive radiographs as negative on scans. Although the three to five agreement left few indeterminate readings, it allowed many "false positive" readings of the chest radiographs. On this basis, the four to five readers in agreement category was used for the study.

RADIOGRAPHS AND COMBINED CCT AND HRCT SCANS For chest radiographs with the four to five reader agreement standard, group A consisted of 36 subjects including the five controls, whose chest radiographs were read as normal (ILO category 0). There were 17 uncertain cases that were neither clearly normal nor clearly abnormal, with less than $80 \%$ agreement between readers. These 17 cases

Table 1 Diffuse small irregular opacities compatible with asbestosis

\begin{tabular}{|c|c|c|c|c|}
\hline Assessment & Chest radiograph & $C T$ scan & & Final assessment \\
\hline \multicolumn{5}{|c|}{ Agreement of three out of five readers } \\
\hline & & Negative & $34(74)$ & \\
\hline Negative(\%) & $46(70)$ & Indeterminate & $0 \quad(0)$ & $40(61)$ \\
\hline & & $\begin{array}{l}\text { Positive } \\
\text { Negative }\end{array}$ & $\begin{array}{rr}12 & (26) \\
0 & (0)\end{array}$ & \\
\hline Indeterminate(\%) & $2 \quad(3)$ & Indeterminate & 0 (0) & $0 \quad(0)$ \\
\hline & & $\begin{array}{l}\text { Positive } \\
\text { Negative }\end{array}$ & $\begin{array}{l}2(100) \\
6 \quad(33)\end{array}$ & \\
\hline Positive(\%) & $18(27)$ & Indeterminate & $0 \quad(0)$ & $26(39)$ \\
\hline Agreement of three out of five readers(\%) & $64(97)$ & Positive & $\begin{array}{l}12(100) \\
66(100)\end{array}$ & $66(100)$ \\
\hline \multicolumn{5}{|c|}{ Agreement of four out of five readers } \\
\hline & & Negative & $26(72)$ & \\
\hline Negative(\%) & $36(54)$ & Indeterminate & $6(17)$ & $33(50)$ \\
\hline & & $\begin{array}{l}\text { Positive } \\
\text { Negative }\end{array}$ & $\begin{array}{l}4(11) \\
6(35)\end{array}$ & \\
\hline & & $\begin{array}{l}\text { Positive } \\
\text { Negative }\end{array}$ & $\begin{array}{l}6(35) \\
1(8)\end{array}$ & \\
\hline Positive(\%) & $13(20)$ & Indeterminate & $2(15)$ & $20(30)$ \\
\hline Agreement of four out of five readers(\%) & $49(74)$ & sive & $\begin{array}{l}10(77) \\
53(80)\end{array}$ & $53(80)$ \\
\hline
\end{tabular}


Table 2 Lung function tests on chest radiograph groups based on four to five reader agreement

\begin{tabular}{|c|c|c|c|}
\hline & $\begin{array}{l}\text { Negative } \\
(n=32)\end{array}$ & $\begin{array}{l}\text { Indeterminate } \\
(n=17)\end{array}$ & $\begin{array}{l}\text { Positive } \\
(n=13)\end{array}$ \\
\hline $\begin{array}{l}\text { Age (y) } \\
\text { TLC (\% predicted) } \\
\text { VC (\% predicted) } \\
\text { FRC (\% predicted) } \\
\text { RV (\% predicted) } \\
\text { FVC (\% predicted) } \\
\text { FEV }(\% \text { predicted }) / s \\
\text { MMEF (\% predicted) } \\
\text { DLCO }\left(\% \text { predicted) } \text { Resting P(A-a) } \mathrm{O}_{2} \text { (torr) }\right. \\
\text { Pleural disease score (index) }\end{array}$ & $\begin{array}{l}60(1) \\
98(3) \\
96(3) \\
91(5) \\
98(7) \\
95(3) \\
97(4) \\
60(5) \\
98(4) \\
21(1) \\
3.3(0.4)\end{array}$ & $\begin{array}{l}62(2) \\
100(4) \\
94(4) \\
102(6) \\
109(8) \\
91(3) \\
87(6) \\
47(6) \\
82(5)^{\star} \\
23(2) \\
4 \cdot 3(0 \cdot 7)\end{array}$ & $\begin{array}{l}62(2) \\
77(4)^{\star} \\
80(6)^{\star} \\
73(6) \\
72(5) \\
83(6) \\
79(8) \\
42(9) \\
78(4)^{\star} \\
27(4) \\
8 \cdot 5(1 \cdot 4)^{\star}\end{array}$ \\
\hline
\end{tabular}

${ }^{\star} \mathrm{p}<0.05 v$ negative. $\mathrm{P}(\mathrm{A}-\mathrm{a}) \mathrm{O}_{2}=$ alveolar-arterial $\mathrm{PO}_{2}$ gradient: see text for other abbreviations; values are mean (SEM).

constituted group B. The 13 remaining cases had an abnormal chest radiograph of category 1 consistent with the diagnosis of asbestosis. They made up group C. Table 2 shows the pulmonary function tests of the three groups. The patients with positive chest radiographs had changes of a significant restrictive syndrome, in comparison with the patients with negative chest radiographs. The only significant change in the patients with indeterminate radiographs was a reduction in diffusion capacity.

With the combined readings of CCT and HRCT scans and the four to five reader agreement category the same 66 subjects were classified as follows: the 36 subjects of the chest radiograph group A were divided into a subset of 26 cases $(72 \%)$ with normal CT scans, a subset of six cases with indeterminate CT scans, and a subset of four cases (11\% of the 36 of the group or $13 \%$ of the 31 asbestos exposed subjects of the group) with abnormal CT scans suggestive of asbestosis (ILO category 1 or above; $\mathrm{p}<0.001$ ); the 17 uncertain cases of group B were divided into a subset of six subjects (35\%) with normal CT scans, a subset of five subjects $(29 \%)$ with indeterminate scans and a subset of six cases $(35 \%)$ with abnormal CT scans, $(p<0.05)$; the 13 cases of asbestosis of group C were divided as follows: one case $(8 \%)$ with a normal CT scan, two cases (15\%) indeterminate, and 10 cases $(77 \%)$ with abnormal CT scans. Table 1 shows this regrouping.

Reconstituting the groups on the basis of the combined reading of the CT scans gives: group 1 , 33 cases $(50 \%)$ with normal CT scans; group 2, 13 cases $(20 \%)$ with indeterminate CT scans; group 3, 20 cases $(30 \%)$ with abnormal CT scans.

To consider the proposal that there were associations between normal radiographs, abnormal scans, and altered lung function, we regrouped the subjects into three groups that could be definitely classified-namely, negative radiograph and negative scan (neg-neg group $(n=26)$; negative radiograph and positive scan (neg-pos group ( $n=$ 10); positive radiograph and positive scan (pos-pos group $(n=10)$. Table 3 shows the pulmonary function tests for these groups. The lung functions of the pos-pos group were significantly altered compared with those of the neg-neg group but the neg-pos group had lung functions that did not differ from those of the neg-neg group. The last finding suggests that, in our subjects, an isolated abnormal CT scan suggestive of asbestosis was not associated with significant changes in lung function.

\section{$C C T$ v HRCT scans}

To carry out independent readings of the CCT and HRCT scans, we selected the 14 scans considered

Table 3 Lung function tests on chest radiograph and CT scan groups based on four to five reader agreement based groups

\begin{tabular}{|c|c|c|c|}
\hline & $\begin{array}{l}N E G-N E G \\
(n=26)\end{array}$ & $\begin{array}{l}\text { NEG-POS } \\
(n=10)\end{array}$ & $\begin{array}{l}\text { POS-POS } \\
(n=10)\end{array}$ \\
\hline $\begin{array}{l}\text { Age y } \\
\text { TLC (\% predicted) } \\
\text { VC (\% predicted) } \\
\text { FRC (\% predicted) } \\
\text { RV (\% predicted) } \\
\text { FVC (\% predicted } \\
\text { FEV } 1 \% \text { predicted) } \\
\text { MMEF (\% predicted) } \\
\text { DLCO (\% predicted) } \\
\text { Resting P[A-a] } \text { O }_{2} \text { (torr) } \\
\text { Pleural disease score }\end{array}$ & $\begin{array}{l}58(2) \\
95(4) \\
94(3) \\
86(6) \\
96(10) \\
93(3) \\
96(4) \\
63(7) \\
95(4) \\
20(1) \\
2 \cdot 9(0 \cdot 5)\end{array}$ & $\begin{array}{l}63(2) \\
104(5) \\
100(6) \\
102(6) \\
110(5) \\
96(5) \\
91(7) \\
43(5) \\
95(7) \\
25(2) \\
5 \cdot 4(0 \cdot 7) \star\end{array}$ & $\begin{array}{l}62(3) \\
75(5)^{\star} \\
79(8) \\
70(5) \\
69(4) \\
82(7) \\
82(9) \\
44(10) \\
76(5)^{\star} \\
27(5) \\
7(1 \cdot 6)^{\star}\end{array}$ \\
\hline
\end{tabular}

${ }^{\star} \mathrm{p}<0.05 v$ NEG-NEG. P[A-a $\mathrm{O}_{2}=$ alveolar-arterial $\mathrm{Po}_{2}$ gradient; see text for other abbreviations; values are mean $(\mathrm{SEM})$. 
positive on the four to five reader agreement basis, with CCT and HRCT on distinct films. The CCT scan and the HRCT scan images were read independently of each other and by each reader alone in one session.

For reading the CCT or the HRCT positive or negative, kappa values were $0.84(0.02)$ for the CCT and $0.73(p<0.05)$ for the HRCT scans.

For small opacities consistent with the diagnosis of asbestosis, separate readings of CCT and HRCT scans did not show cases of asbestosis on the combined CT scan readings (table 1) that were abnormal only on the CCT or abnormal only on the HRCT. The readings of the CCT had better reader agreement but the averages of the readings were less uniform among the five readers by comparison with the HRCT, suggesting a better definition of images on the HRCT. Again it was considered that the added clarity provided by the HRCT images permitted more rapid decision making and firmer interpretations of the images in some $30 \%$ of cases of asbestosis recognised by CT scan.

\section{MULTIPLE VARIATE ANALYSES}

For parenchymal disease scores on radiographs and on CT scans, there were significant associations with total lung capacity (TLC), vital capacity (VC), DLCO, maximum mid-expiratory flow (MMEF), years of asbestos exposure, and pleural disease score $(p<0.05)$ but no association with smoking index, forced expiratory volume in one second $\left(\mathrm{FEV}_{1}\right)$ /forced vital capacity (FVC), or residual volume (RV/TLC.)

We found no significant associations between pleural disease score and smoking or loss of lung function, but there was a significant association with the number of years of exposure to asbestos $(\mathrm{p}<0.02)$.

For the indicators of airflow limitation, the expiratory flow rates, we found no significant association with parenchymal or pleural scores of disease or years of exposure to asbestos but significant associations with the smoking index for $\mathrm{FEV}_{1} / \mathrm{FVC}$ $(\mathrm{p}<0.0001)$, MMEF $(\mathrm{p}<0.03)$, the RV $(\mathrm{p}<0.007)$, and RV/TLC $(\mathrm{p}<0.005)$.

For the indicators of restriction, TLC, VC, and DLCo, we found no significant association with smoking but significant associations with years of exposure in asbestos, $\mathrm{CR}$ and $\mathrm{CT}$ scan scores of parenchymal disease $(p<0.05$ for TLC and VC and $p>0.05$ for DLCO and years of exposure to asbestos; $p<0.05$ for TLC and VC; $p<0.003$ for DLCo and CR score; $p>0.05$ for TLC; $p<0.02$ for VC, DLCO, and CT scan score.

\section{Discussion}

In this study of 61 workers at risk of asbestosis, the combined reading of CCT and HRCT scans in subjects exposed to asbestos detected interstitial lung abnormalities consistent with asbestosis in $19 \%$ of subjects with a normal or indeterminate radiograph. For the normal chest radiographs, 13\% of cases were positive on CT scans. Although we do not have histological proof, we believe that these small irregular opacities seen in asbestos workers with normal radiographs are early asbestosis lesions for the following reasons:

(1) in normal subjects, the incidence of small opacities on chest radiographs is $<1 \%{ }^{34}$; and this is also the clinical experience of ourselves and others with the CT scans ${ }^{26}$; even in long term cigarette smokers, the prevalence of definite radiological opacities of the lung parenchyma (ILO category $\geqslant 1 / 0$ ) is only $3 \% .{ }^{35}$

(2) The five normal unexposed subjects did not have small opacities and all readers agreed on that.

(3) the opacities in asbestosis were often limited radiographically to the lower lung fields, their distribution was usually fairly symmetrical in the right and left lung fields (figs 1 and 2 illustrate cases with normal radiographs and abnormal CT scans suggestive of asbestosis) and the opacities have some features that often differentiate them from those of idiopathic pulmonary fibrosis ${ }^{36}$; that opacities should be bilateral was an obligatory criterion in this study.

(4) The global appearance of these small opacities on CT described by independent groups ${ }^{22} 2327-30$ was comparable with what is known of asbestosis histologically, ${ }^{13} 37$ and on the standard chest radiograph for more advanced disease. ${ }^{2} 3$

(5) The CT scan has detected changes in other interstitial lung diseases before they were detected on the standard chest radiograph..$^{78202131}$

(6) The inter-reader agreement for the recognition of these opacities on the CT scans was significantly higher than for the conventional chest radiograph, despite the absence of reference CT films for comparison.

(7) In the sheep model of asbestosis, the disease process found, within the first few months of exposure in susceptible animals, by lung lavage, lung biopsies, and gallium-67 scan, was only seen on standard chest radiographs one to two years later in the evolution of the disease process. ${ }^{38-41}$

The subjects with a normal radiograph but abnormal CT scan suggestive of asbestosis had no significant changes in lung function tests (table 2). This was at variance with the report of Staples et al $^{22}$ but not unexpected in view of our earlier reports on lung function in the disease $e^{10143942}$ and from other publications on this subject, ${ }^{43-45}$ which state that appreciable changes in lung function are usually absent in the early stage of asbestosis that precedes radiographic manifestations. Further- 
more, it is of interest that among the subjects with normal chest radiographs, five of the six patients of Epler $e t a l$ and six out of six of ours with histological asbestosis had near normal or normal lung function at rest. ${ }^{10363942}$ Functional abnormalities in our subjects were a rigid pressure-volume curve in $75 \%$ and abnormal exercise gas exchanges in $50 \%$, which did not reach significance because of the small number of patients $(50 \%)$ who agreed to perform these additional tests. In more advanced stages of disease, the changes in lung function generally correlated with the scored abnormalities on the radiograph and on the CT scan. ${ }^{14}{ }^{23}$

What does HRCT add to CCT? Firstly, it must
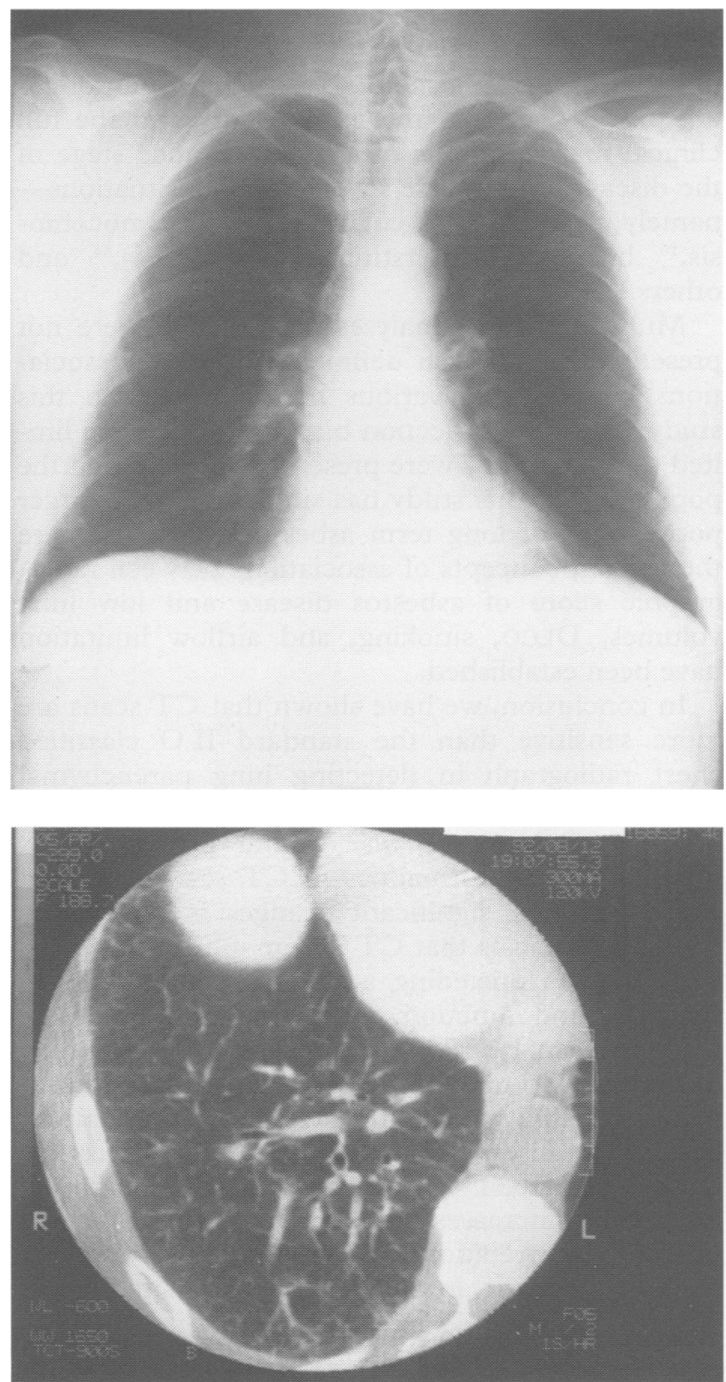

be recognised that the recent generation of scanners has better spatial and contrast resolution both on CCT and HRCT than earlier machines. Secondly, it is accepted that, for the analysis of this issue, the sample size of 14 subjects and the limited number of thin CT slices may not permit definite conclusions. Thirdly, the 14 cases used to evaluate the two types of scanner were on separate films and read independently. For small irregular opacities, both techniques permitted the recognition of disease equally well, which is at variance with the report of Rémy-Jardin et al for cases of diffuse interstitial diseases of non-occupational origin, where $22 \%$ of all infiltrates were not recognised on thin sections. ${ }^{46}$ In this study the CCT and HRCT were considered abnormal equally in all cases of asbestosis, and by at least four of the readers. The agreement between readers was high for positive or negative readings, notwithstanding comparable $(p>0.05)$ average scorings by each reader for the two modes. Despite this, it was considered by all readers that the HRCT added precision and clarity to the findings in up to $30 \%$ of cases, where classification of the images was done with less hesitation and with a higher degree of confidence. This was also found in earlier studies.

It is medically accepted that early detection and diagnosis of asbestosis in individual cases should be based on the most acceptable set of clinical criteria, at a time when the disease is not yet disabling and is less likely to progress to invalidity. This is based on the current understanding, supported by experimental data, that the most susceptible subjects who already have the disease should not be further exposed to the disease inducer. ${ }^{47}$ In recent years, we and others have shown repeatedly, and in diverse populations exposed long term to asbestos,

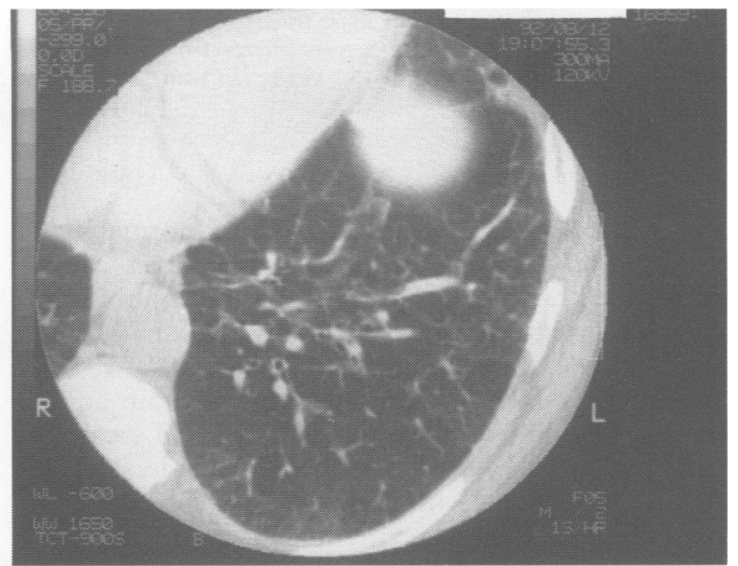

Figure 1 Chest radiograph (upper panel) and high resolution CT scan (lower panels) in an exposed subject. The chest radiograph was read as normal and the CT scan as definitely abnormal, with bilateral diffuse subpleural reticular infiltrations in the dependent and non-dependent areas. These changes were read as in the category $1 / 1$ on CT scan. 

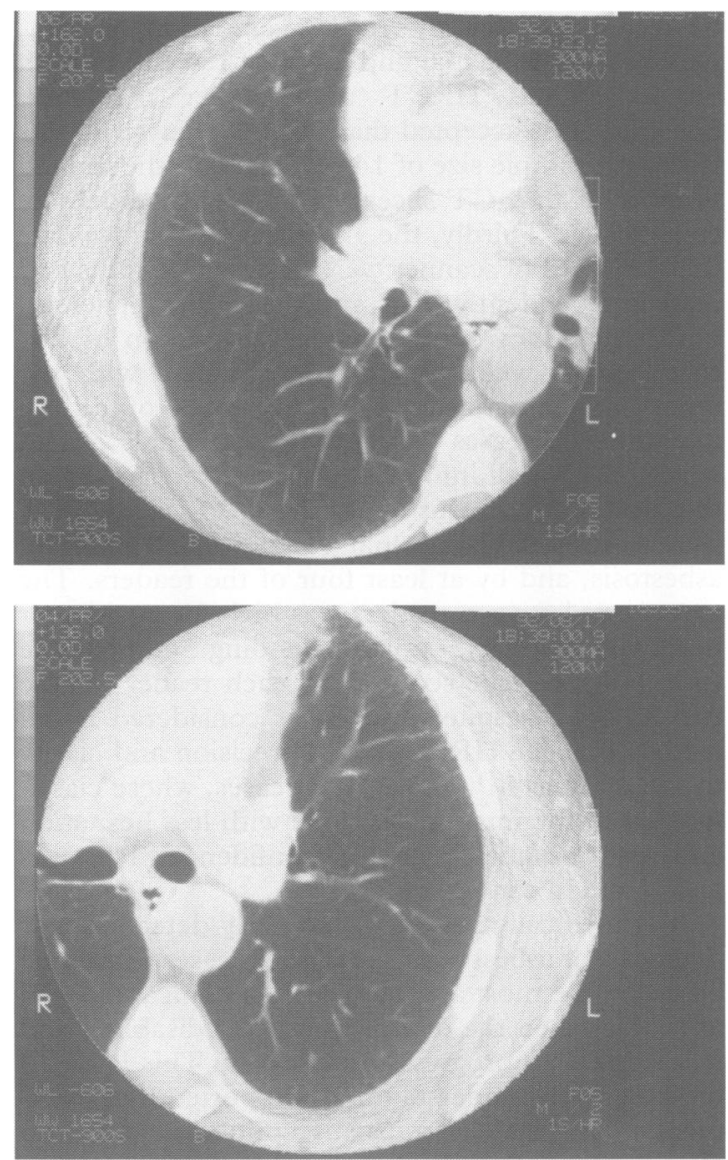

Figure 2 High resolution CT scan of the lower left (upper panel) and right (lower panel) lung fields in an exposed subject (different from the subject in fig 1) with a normal chest radiograph. As in fig 1, the subpleural reticular infiltrates were considered diffuse in the dependent and non-dependent areas. Also, a small pleural plaque is seen in the paravertebral area, and the lung infiltrates appear more intense in this area. The parenchymal lung abnormalities were interpreted as less intense than in fig 1 and were classified as in the ILO category 110 on the $C T$ scan.

that before asbestosis produces an abnormal chest radiograph, the ongoing asbestosis process can be recognised histologically, ${ }^{9-11}$ by analysis of bronchoalveolar lavage fluids, ${ }^{36-39} 43-4548$ by gallium-67 lung scan, ${ }^{1049-51}$ and by CT scans ${ }^{22} 27-30$ in $10 \%-40 \%$ of such workers. This was also validated in our animal model for all techniques except the CT scan. In this paper, we have shown that the readers' agreement can influence the results of such studies, but with the stringent agreement of four to five independent readers, we still find a significant $13 \%$ incidence of negative radiographs and positive $\mathrm{CT}$ scans in subjects exposed long term to asbestos, seen in the setting of a workman compensation examination. Given that the CT scan procedure has better patient acceptance and gives results in the same range as alternative detection techniques for early disease, we consider the CT scan to be the procedure of first choice for subjects exposed long term to asbestos and suspected of having asbestosis despite a normal or near normal chest radiograph.

The management of cases of asbestosis detected by abnormal scans only is controversial. Some would argue that the abnormalities found may represent non-specific changes and do not relate to the previously established prognosis of asbestosis defined by the more rigid criteria of an abnormal radiograph of category $2 / 1$ or $1 / 1 .^{52}$ Others would reply that these changes constitute manifestations brought forward by the more sophisticated technologies of the 1980s and 90s that reflect an ongoing process between the initial injury and the full clinical manifestations of a more advance stage of the disease. ${ }^{27}$ There are several parallel situationsnamely, in silicosis, ${ }^{2153}$ coal workers' pneumoconiosis, ${ }^{20}$ bleomycin interstitial lung fibrosis, ${ }^{54}$ and others. ${ }^{78}$

Multiple variate analyses of our data were not presented to establish definite and strong associations between the various measurements in this study, as it has a selection bias and there were limited samples. They were presented to show that the population of this study has similarities with larger populations of long term asbestos workers, where the current concepts of associations between radiographic score of asbestos disease and low lung volumes, DLCo, smoking, and airflow limitation have been established.

In conclusion, we have shown that CT scans are more sensitive than the standard ILO classified chest radiograph in detecting lung parenchymal changes of asbestosis. This agrees with the earlier findings of Staples et al. ${ }^{22}$ In our present study, however, the abnormalities in CT scans were not associated with significant changes in lung function; this suggests that CT in our subjects detected early disease preceding appreciable alterations in structure and function. The abnormalities of the CT scan can be recognised more consistently by independent trained observers, with reduced interreader variability compared with their radiographs, despite the absence of standard ILO type reference films. The HRCT scan adds to the CCT clarity of images and increases the confidence of the readers in their interpretations, although with lower interreader agreement, in the recognition of small irregular opacities.

The work was supported by the Medical Research Council of Canada. We thank Ms Marielle Ste-Marie for her help in the retreival of several of the cases of this study. 
Request for reprints to: $\mathrm{R}$ Bégin, $\mathrm{MD}, \mathrm{CHU}$ Sherbrooke, Québec, Canada J1H 5N4.

1 International Labour Organisation/ University of Cincinnati. International classification of radiographs of pneumoconioses Geneva: International Labour Office, 1980. (Occupational safety and health series. No 22 revised.)

2 Ostiguy G (chairman) for the task force on occupational respiratory disease: Health and welfare Canada. Ottawa: Canadian Government Publication. 1979:35-48.

3 Murphy RL, Becklake MR, Brooke SM, et al. The diagnosis of nonmalignant diseases related to asbestos. Am Rev Respir Dis 1986;134:363-8.

4 Zerhouni E. Computed tomography of the pulmonary parenchyma. Chest 1989;95:901-7.

5 Nakata H, Kimoto T, Nakayama T, Kido M, Miyazaki N, Harada S. Diffuse peripheral lung disease: evaluation by high-resolution computed tomography. Radiology 1985;157:181-5.

6 Müller NL, Miller RR, Webb WR, Evans KG, Ostrow DN. Fibrosing alveolitis: CT-pathologic correlation. Radiology 1986;160:585-8.

7 Mathieson JR, Mayo JR, Staples CA, Müller N. Chronic diffuse infiltrative lung disease: comparison of diagnostic accuracy of CT and chest radiography. Radiology 1989;171: $111-6$.

8 Généreux GP. The Fleischner lecture: Computed tomography of diffuse pulmonary disease. $\mathcal{F}$ Thorax Imaging 1989;4: $50-87$.

9 Epler GR, McLoud T, Gaensler EA, Mikus JP, Carrington CB. Normal chest roentgenograms in chronic infiltrative lung disease. $N$ Engl f Med 1978;298:934-9.

10 Bégin R, Cantin A, Drapeau G, et al. Pulmonary uptake of gallium-67 in asbestos exposed humans and sheep. Am Rev Respir Dis 1983;127:623-30.

11 Kipen HM, Lillis R, Suzuki Y, Valciukas JA, Selikoff IJ. Pulmonary fibrosis in asbestos insulation workers with lung cancer: a radiologic and histopathologic correlation. $\mathrm{Br} \mathcal{F}$ Ind Med 1987;44:934-9.

12 Rockoff SD, Schwartz A. Roentgenographic underestimation of early asbestosis by the international labor organization classification. Analysis of data and probabilities. Chest 1988;93:1088-91.

13 Craighead JE, Abraham JL, Churg A, et al. The pathology of asbestos-associated diseases of the lung and pleural cavities: diagnostic criteria and proposed grading scheme. Arch Pathol Lab Invest 1982;106:544-95.

14 Bégin $\mathrm{R}$, Boctor M, Bergeron D, et al. Radiographic assessment of pleuropulmonary disease in asbestos workers: posteroanterior, four view films, and computed tomograms of the thorax. Br f Ind Med 1984;41:373-83.

15 Bégin R, Bergeron D, Samson L, Boctor M, Cantin A. CT assessment of silicosis in exposed workers. American fournal of Roentgenology 1987;148:509-14.

16 Bégin R, Massé S, Cantin A, Bisson G, Lamoureux G. Imaging the pneumoconioses: A multidisciplinary approach. f Thorax Imaging 1988;3:37-50.

17 Bégin R, Ostiguy G, Cantin A, Bergeron D. Lung function in silica exposed workers: a relationship of disease severity assessed by CT scan. Chest 1988;94:539-45.

18 Bégin R, Cantin A, Massé S. Recent advances in the pathogenesis and clinical assessment of mineral dust pneumoconioses: Asbestosis, silicosis, and coal pneumoconiosis. Eur Respir F 1989;2:988-1001.

19 Bégin R, Ostiguy G, Groleau S, Filion R. CT scanning of the thorax in workers at risk of, or with silicosis. Semin Ultrasound CT MR 1990;2:1-12.

20 Rémy-Jardin M, Degreef JM, Beuscart R, Voisin C, Rémy J. Coal worker's pneumoconiosis: CT assessment in exposed workers and correlation with radiographic findings. Radiology 1990;177:363-71.

21 Bégin R, Ostiguy G, Filion R, Coleman N. CT scan in the early detection of silicosis. Am Rev Respir Dis 1991;144: 697-705.

22 Staples CA, Gamsu G, Ray CS, Webb WR. High resolution computed tomography and lung function in asbestosexposed workers with normal chest radiograph. Am Rev Respir Dis 1989;139:1502-8.
23 Al-Jarad N, Wilkinson P, Pearson MC, Rudd RM. A new high resolution computed tomography scoring system for pulmonary fibrosis, pleural disease, and emphysema in patients with asbestos related disease. $\mathrm{Br} \mathcal{F}$ Ind $\mathrm{Med}$ 1992;49:73-84.

24 Crofton J, Douglas A. Respiratory diseases. Oxford: Blackwell, 1969, 51 .

25 The normal lung: physiology and methods of study. In: Bates DV, Macklem PT, Christie RV, eds. Respiratory function in disease. Philadelphia: WB Saunders 1971: 11-94 and 276-80.

26 Müller N, Miller RR. Computed tomography of chronic diffuse infiltrative lung disease. Am Rev Respir Dis 1991; 142:1206-15 and 1440-8.

27 Bégin R, Ostiguy R, Filion R, Groleau S. Recent advances in the early diagnosis of asbestosis. Semin Roentgenol 1992;27:121-39.

28 Aberle DR, Gamsu G, Ray CS, Feuerstein IM. Asbestosrelated pleural and parenchymal fibrosis: detection with high-resolution CT. Radiology 1988;166:729-34.

29 Akira M, Yokoyama K, Yamamoto S, et al. Early asbestosis: evaluation by high-resolution CT. Radiology 1991; 178:409-16.

30 Friedman AC, Fiel SB, Radecki PD, Lev-Toaff AS. Computed tomography of benign pleural and pulmonary parenchymal abnormalities related to asbestos exposure. Semin Ultrasound CT MR 1991;11:393-408.

31 Snedecor GW, Cochran WO. Statistical methods. Ames, Iowa: Iowa State University Press, 1967.

32 Fleiss JL. Statistical methods for rates and proportions. 2nd ed. New York: John Wiley 1981.

33 Siegel S. Non-parametric statistics. New York: McGraw-Hill 1956, 195-240.

34 Castellan RM, Sanderson WT, Petersen MR. Prevalence of radiographic appearance of pneumoconiosis in an unexposed blue collar population. Am Rev Respir Dis 1985; 131:684-6.

35 Ducatman AM, Withers BF, Yang WN. Smoking and roentgenographic opacities in US navy asbestos workers. Chest 1990;97:810-3.

36 Al-Jarad N, Strickland B, Pearson MC, Rubens MB, Rudd RM. High resolution computed tomographic assessment of asbestosis and cryptogenic fibrosing alveolitis: a comparative study. Thorax 1992;47:645-50.

37 Churg A, Green FHY. Pathology of occupational lung disease. 1st ed. New York: IGAKU-SHOIN 1989, 213-78.

38 Bégin R, Massé S, Rola-Pleszczynski M, Drapeau G. Bronchoalveolar and lung tissue analyses in asbestosexposed humans and sheep. In: Beck EG, Bignon J, eds. In vitro effects of mineral dusts. Heidelberg: Springer-Verlag 1985,359-67.

39 Bégin R, Cantin A, Berthiaume Y, et al. Clinical features to stage alveolitis in asbestos workers. Am F Ind Med 1985; 8:521-36.

40 Bégin R, Martel M, Desmarais Y, et al. Fibronectin and procollagen 3 levels in bronchoalveolar lavage of asbestosexposed human subjects and sheep. Chest 1986;89:237-43.

41 Bégin R, Cantin A, Massé S, Sébastien P. Contributions of sheep experimental asbestosis to the understanding of mechanisms of asbestosis. Ann N Y Acad Sci 1991, 643:228-38.

42 Bégin R, Cantin A, Berthiaume Y, Boileau R, Péloquin S, Massé $S$. Airway function in lifetime-nonsmoking older asbestos workers. Am f Med 1983;75:631-8.

43 Rom WN, Bitterman PB, Rennard SI, Cantin A, Crystal R. Characterization of the lower respiratory tract inflammation of nonsmoking individuals with interstitial lung disease associated with chronic inhalation of inorganic dusts. Am Rev Respir Dis 1987;136:1429-34.

44 Rom WN. Relationship of inflammatory cell cytokines to disease severity in individuals with occupational inorganic dust exposure. Am $\mathcal{F}$ Ind Med 1991;19:15-27.

45 Robinson BWS, Rose AH, James A, Whitaker D, Musk AW. Alveolitis of pulmonary asbestosis. Bronchoalveolar lavage studies in crocidolite- and chrysotile-exposed workers. Chest 1986;90:396-402.

46 Remy-Jardin M, Remy J, Deffontaines C, Duhamel A. Assessment of diffuse infiltrative lung disease: comparison of conventional CT and high-resolution CT. Radiology 1991;181:157-62.

47 Bégin R, Cantin A, Massé S. Influence of continued asbestos exposure on the outcome of asbestosis in sheep. Exp Lung 
Research 1991:17:971-84.

48 Spurzem JM, Saltini C, Rom W, Winchester RJ, Crystal RG. Mechanisms of macrophage accumulation in the lung of asbestos exposed subjects. Am Rev Respir Dis 1987; 136:276-80.

49 Bisson G, Drapeau G, Lamoureux G, Bégin R. Computerbased quantitative analysis of Gallium-67 uptake in normal and diseased lungs. Chest 1983;84:513-7.

50 Bisson G, Lamoureux G, Bégin R. Quantitative Gallium-67 lung scan to assess the inflammatory activity in the pneumoconioses. Semin Nucl Med 1987;17:72-80.

51 Hayes AA, Mullen B, Lovegrove F, Rose AH, Musk AW, Robinson BWS. Gallium lung scanning and bronchoalveo- lar lavage in crocidolite-exposed workers. Chest 1989; 96:22-6.

52 Harber P, Smitherman J. Asbestosis: diagnostic dilution. f Occup Med 1991;33:786-93.

53 Craighead JE, Vallyathan NV. Cryptic pulmonary lesions in workers occupationally exposed to dust containing silica. FAMA 1980;244:1939-41.

54 Bellamy EA, Husband JE, Blaquiere RM, Law MR Bleomycin-related lung damage: CT evidence. Radiology 1985;156:155-8.

Accepted 22 February 1993

\section{Vancouver style}

All manuscripts submitted to the $B r \mathcal{F}$ Ind Med should conform to the uniform requirements for manuscripts submitted to biomedical journals (known as the Vancouver style.)

The $\mathrm{Br} \mathcal{F}$ Ind $\mathrm{Med}$, together with many other international biomedical journals, has agreed to accept articles prepared in accordance with the Vancouver style. The style (described in full in $\mathrm{Br}$ Med f, 24 February 1979, p 532) is intended to standardise requirements for authors.

References should be numbered consecutively in the order in which they are first mentioned in the text by Arabic numerals above the line on each occasion the reference is cited (Manson ${ }^{1}$ confirmed other reports ${ }^{2-5} \ldots$. . . In future references to papers submitted to the $\mathrm{Br} \mathcal{F}$ Ind $M e d$ should include: the names of all authors if there are six or less or, if there are more, the first three followed by et al; the title of journal articles or book chapters; the titles of journals abbreviated according to the style of Index Medicus; and the first and final page numbers of the article or chapter.

Examples of common forms of references are:

1 International Steering Committee of Medical Editors, Uniform requirements for manuscripts submitted to biomedical journals. $B r$ F Ind Med 1979;1:532-5.

2 Soter NA, Wasserman SI, Austen KF. Cold urticaria: release into the circulation of histamine and eosinophil chemotactic factor of anaphylaxis during cold challenge. $N$ Engl $\mathcal{f}$ Med 1976;294:687-90.

3 Weinstein L, Swartz MN. Pathogenic properties of invading micro-organisms. In: Soderman WA Jr, Soderman WA, eds. Pathologic physiology, mechanisms of disease. Philadelphia: $W$ B Saunders, 1974:457-72. 